\title{
MOTIVAÇÕES, DIFICULDADES E EXPECTATIVAS ACERCA DA ADOÇÃO: PERSPECTIVAS DE FUTUROS PAIS ADOTIVOS
}

MOTIVATIONS, DIFFICULTIES AND EXPECTATIONS REGARDING ADOPTION: PERSPECTIVES OF PROSPECTIVE ADOPTIVE PARENTS

MOTIVACIONES, DIFICULTADES Y EXPECTATIVAS SOBRE LA ADOPCIÓN: PERSPECTIVAS DE FUTUROS PADRES ADOPTIVOS

\author{
Ana Isabel dos Santos Félix Araujo* \\ André Faro ${ }^{* *}$
}

\begin{abstract}
RESUMO
O presente estudo objetivou delinear motivos, dificuldades e expectativas em torno do futuro filho na perspectiva de pais candidatos ao processo de adoção, como também, caracterizar o perfil da criança pretendida em uma Vara da Infância e Juventude de Aracaju (SE). Entrevistaram-se 13 candidatos a pais adotivos (monoparentais e casais), a partir dos seguintes eixos temáticos: motivações para a adoção; preferências quanto à criança; expectativas concernentes à adoção; e medos e receios em torno da adoção. As falas foram analisadas com o software IRAMUTEQ. Os resultados reiteraram a complexidade subjetiva do processo de adoção, em especial pelo embate entre fantasia e realidade no que toca à futura adaptação à nova família. Ademais, houve preferência por meninas, brancas ou pardas e menores que cinco anos. Conclui-se que compreender a forma pela qual os adotantes significam a adoção pode auxiliar no delineamento de ações mais apropriadas de orientação e aconselhamento na temática.
\end{abstract}

Palavras-chave: Adoção. Motivação. Dificuldades. Expectativas.

\begin{abstract}
This study aimed to delineate motives, difficulties and expectations about future child from the perspective of parents' candidates to the adoption process, and to characterize the profile of the desired child atInfancy and Youth Judgeship of Aracaju (SE). We interviewed 13 candidates for adoptive parents (singles and couples), based on the following themes: motivations for adoption; preferences for the child; expectations concerning the adoption; and fears about the adoption. The answers were analyzed by IRAMUTEQ software. The results reiterated the subjective complexity of the adoption
\end{abstract}

\footnotetext{
Texto recebido em 03 de agosto de 2014 e aprovado para publicação em 05 de novembro de 2015 .

Psicóloga, Departamento de Psicologia da Universidade Federal de Sergipe (UFS).E-mail: aisabelpsi7@gmail.com

* Professor Adjunto do Departamento de Psicologia (DPS) e do Mestrado em Psicologia (PPGPSI) da Universidade Federal de Sergipe (UFS). E-mail: andre.faro.ufs@gmail.com
} 
process, in particular by the clash between fantasy and reality with regard to future adjustment to the new family. Furthermore, there was a preference for girls, white or brown and less than five years old. We conclude that understanding the mean adoption for adopters can help to delineate more appropriate actions for guidance and advice on this question.

Keywords: Adoption. Motivation. Difficulties. Expectations.

\section{RESUMEN}

Este estudio objetivó delinear motivaciones, dificultades y expectativas sobre el futuro del niño desde la perspectiva de padres candidatos al proceso de adopción, pero también caracterizar el perfil del niño pretendido en un Juzgado de la Infancia y Juventud de Aracaju (SE). Entrevistamos 13 candidatos a padres adoptivos (solteros y parejas), con los temas: motivaciones para la adopción; preferencias por el niño; expectativas relativas a la adopción; y miedos y temores acerca de la adopción. Los discursos fueron analizados con el software IRAMUTEQ. Los resultados reiteran la complejidad subjetiva del proceso de adopción, en particular, el choque entre fantasía y realidad con respecto a la futura adaptación a la nueva familia. Además, hubo preferencia por niñas, blancas o pardas y menores de cinco años. Se concluyó que la comprensión del modo que los adoptantes representan la adopción puede ayudar a delinear acciones más apropiadas para orientación en el tema.

Palabras clave: Adopción. Motivaciones. Dificultades. Expectativas.

\section{INTRODUÇÃO}

adoção de crianças no Brasil não é simples ou fácil de ser concretizada ainda que - a cada ano - o número de famílias interessadas em adotar uma criança continue aumentando, bem como a quantidade de crianças à espera de uma família. De acordo com levantamento de dados recentes do Cadastro Nacional de Adoção (CNA), divulgado pelo Conselho Nacional de Justiça (CNJ), em agosto de 2012, havia 5.281 crianças aptas a serem adotadas em todo o Brasil; 28.151 pretendentes interessados em adotar (Conselho Nacional de Justiça [CNJ], 2013). No entanto, apesar das condições aparentemente favoráveis, com uma proporção de mais de cinco casais por criança, existem crianças à espera de uma família há muito tempo e -, possivelmente - permanecerão nesta condição, principalmente se não corresponderem ao perfil idealizado pela maioria dos pretensos pais (Costa \& Campos, 2003). 
A Nova Lei da Adoção (Lei no 12.010, 2009) tem como objetivo privilegiar o direito da criança de viver em uma família - biológica ou substituta - evitando, com isso, que ela seja esquecida na instituição, e garantindo que as suas necessidades sejam favorecidas. O termo adoção, segundo Mariano e RossettiFerreira (2008), constitui-se em uma das formas de colocação de crianças e/ou adolescentes em uma família substituta, pressupondo a perda do poder familiar pelos pais biológicos e a aquisição de um novo vínculo de filiação pela criança. Para que esse processo ocorra por vias legais - primeiramente - a pessoa (ou casal) com interesse em adotar legalmente uma criança ou adolescente deve se cadastrar em um Juizado. Assim, os requerentes à adoção têm a possibilidade de, ao preencher o Cadastro de Adoção, indicar características do pretenso adotável sexo, cor de pele, idade e aspectos de saúde.

A pesquisa realizada pelo $\mathrm{CNJ}$ (2013) revelou que a idade é o principal motivo de desencontro entre as preferências do pretendente e as características das crianças e dos adolescentes que aguardam por uma adoção no Brasil. Destaca-se que nove em cada dez pretendentes desejam adotar uma criança de zero a cinco anos, enquanto essa faixa etária corresponde a apenas nove em cada 100 das crianças aptas à adoção. Essa pesquisa identificou que há mais crianças com idade acima dos cinco anos que continuam institucionalizadas, sem perspectiva de serem colocadas em famílias substitutas por apresentarem características pouco desejáveis: serem negras, apresentarem deficiências, terem problemas de saúde ou formarem grupo de irmãos. Logo, o processo de escolha das características do filho adotivo está marcado por uma dinâmica social na qual estão envolvidos estereótipos que geram expectativas por parte dos adotantes; afetando - assim a probabilidade das adoções ocorrerem (Amim \& Menandro, 2007; Ishizawa \& Kubo, 2014; Jerome \& Sweeney, 2014; Merçon-Vargas, Rosa, \& Dell'Áglio, 2011).

Os motivos que levam as pessoas a procurarem pela adoção são inúmeros, tais como dificuldade de engravidar, desejo de ser pai/mãe, o sentimento altruísta de dar uma família para uma criança, ter uma companhia, entre outros. No entanto, pesquisas mostram que a infertilidade é um dos principais motivos para que os indivíduos se candidatem à adoção (Gondim, et al., 2008; Mariano \& Rossetti-Ferreira, 2008; Salvaterra \& Veríssimo, 2008; Schetinni, Amazonas, \& Dias, 2006; Silva, Mesquita, \& Carvalho, 2010; Vanalli \& Santana, 2009).

O tema adoção é permeado por dúvidas, mitos e preconceitos, que devem ser esclarecidos com o objetivo de minimizar pressuposições equivocadas, que dificultam o processo, como também promover reflexôes sobre a realidade do ato de adotar. Alguns dos aspectos que usualmente causam preocupação para os 
adotantes são as dúvidas dos pais a respeito da herança biológica na determinação do comportamento, o medo da revelação da condição de adotado e o receio quanto à adaptação nas adoções tardias (Merçon-Vargas, et al., 2011; Otuka, Scorsolini-Comin, \& Santos, 2013; Santos, 2010).

Internacionalmente o foco das pesquisas não se mostra tão distante do que se conduz no Brasil; em particular, pela ênfase em torno das dificuldades de ajustamento ao longo do desenvolvimento em virtude da condição de adotado e as adoções em situações específicas, tal como por casais homoparentais (Denby, Alford, \& Ayala, 2011; Grotevant \& McDermott, 2014; Ishizawa \& Kubo, 2014; Sánchez-Sandoval \& Palacios, 2012).

As representações de família presentes no imaginário social fundamentam-se nos laços consanguíneos, sendo que a maioria das pessoas acredita no fato de que ser adotado já é condição suficiente para ser classificado como problemático, diferente e fora do normal (Schettini, Amazonas, \& Dias, 2006; Silva, 2009). De acordo com Puretz e Luiz (2007), os mitos que constituem a adoção no Brasil estabelecem crenças e expectativas negativas ligadas à prática da adoção, e se apresentam como impedimentos à realização de adoções de crianças maiores e adolescentes.

Reppold e Hutz (2003) classificam as motivações em: altruístas, relacionadas ao desejo social de beneficiar uma criança ou um adolescente, e hedonistas, aquelas relacionadas ao desejo pessoal de ter um filho. Neste sentido, no estudo de Ebrahim (2001), observou-se que a motivação hedonista foi mais significativa que a altruísta, indicando que o principal motivador para a adoção é o desejo de ser pai e mãe. A motivação sempre deve ser um fator de investigação dos candidatos, e que o motivo maior deve ser o grande desejo de transformar uma criança com qual não se compartilham laços de sangue em filho (Weber 2011).

Considerando os aspectos envolvidos em torno da adoção, e compreendendo que são complexas e multideterminadas as razões que justificam as escolhas do perfil da criança/adolescente pelos pretendentes, julga-se necessária a investigação acerca dos motivos, dificuldades e expectativas que influenciam o adotante a se cadastrar para adoção. Diante disso, a prática da adoção de crianças requer tanto da família adotante quanto da criança pretendida uma profunda capacidade de adaptação.

Gondim et al. (2008) afirmam que o trabalho de preparo com os pretendentes à adoção possibilita que eles repensem as suas exigências quanto às características (físicas e psicológicas) da criança desejada, de modo a facilitar o processo e ampliar as possibilidades de adotantes e adotáveis. $\mathrm{O}$ acompanhamento psicológico também pode atuar visando conscientizar os pais acerca da importância de 
conhecer as dificuldades, expectativas e motivações dos pretendentes à adoção. Estas questôes devem ser consideradas antes de um casal se candidatar a adotar uma criança, assim como os fatores de risco envolvidos, os mitos e preconceitos existentes no imaginário da sociedade que podem contribuir para a devolução (Silva \& Silva, 2012). Portanto, a escuta dos candidatos à adoção torna-se elemento fundamental para perceber como eles articulam suas percepções em torno da adoção. Considerando-se o então exposto, o presente estudo teve como objetivo delinear os motivos, dificuldades e expectativas em torno do futuro filho na perspectiva desses pretendentes à adoção, como também, caracterizar o perfil da criança pretendida em uma Vara da Infância e Juventude de Aracaju (SE).

\section{MÉTODO}

\subsection{Participantes}

Participaram deste estudo pessoas interessadas em adotar crianças ou adolescentes cadastradas em uma Vara da Infância e da Juventude de Aracaju (SE). O critério de seleção foi o de pessoas (casais, sendo uma pessoa por casal, ou indivíduos) que pretendiam adotar pela $1^{\mathrm{a}}$ vez, independentemente de já terem filhos biológicos. Dos76 pretendentes habilitados à adoção - constantes na lista de cadastro dos anos de $2012(n=38 ; 50 \%)$ e $2013(n=38 ; 50 \%)$ - apenas 13 se disponibilizaram $(17,1 \%)$. Os principais motivos para esse montante foram a alegação de falta de tempo para a entrevista e a recusa direta à participação.

\subsection{Instrumentos e Procedimentos}

Realizaram-se entrevistas apoiadas em roteiro aberto, baseadas nos seguintes eixos temáticos: motivaçóes dos pretendentes com relação à adoção; preferência quanto às características da criança adotada; expectativas concernentes à adoção; por fim, receios em torno do processo da adoção. A partir de cada eixo temático, foi feita uma pergunta aberta em que os participantes respondiam livremente com o que se aprofundava o tema com outras questôes. Além disto, foram obtidos alguns dados a respeito do perfil da criança pretendida por meio do Cadastro de Adoção e relato dos indivíduos entrevistados.

Após a autorização do Juizado, teve-se acesso ao cadastro dos adotantes. Com isso, foi possível entrar em contato com os mesmos por telefone, marcando dia e horário para que as entrevistas fossem realizadas em local definido pelos pretendentes à adoção. Os participantes foram informados não só do objetivo da 
investigação como foram esclarecidos de que a pesquisa se constituiu de atividade independente do processo em curso, e que as informações coletadas e as opiniōes manifestadas não tiveram qualquer repercussão sobre o referido processo. Para tanto, foi apresentado aos participantes o Termo de Consentimento Livre e Esclarecido (TCLE), aos quais foi garantido o direito à confidencialidade dos dados, sigilo das identidades e possibilidade de retirar seu consentimento em qualquer momento.

\subsection{Análise de dados}

As entrevistas foram transcritas na íntegra e analisadas através do software Interface de R pourles Analyses Multidimensionnelles de Textes et de Questionnaires (IRAMUTEQ). O IRAMUTEQ é um software informatizado para análise de textos que busca apreender a estrutura e a organização do discurso, informando as relações entre léxicos mais frequentesnos enunciados dos sujeitos. Dentre as análises disponíveis, optou-se pela Classificação Hierárquica Descendente (CHD) e dendograma de classes (Camargo \& Justo, 2013).

A análise foi executada a partir de um corpus único em que foram relacionadas todas as entrevistas. A CHD permite a análise de segmentos de textos que apresentam vocabulário semelhante entre si e vocabulário diferente de outros segmentos de texto, simultaneamente, calculando distancias e proximidades a partir de testes do Qui-Quadrado. Com essas análises, o IRAMUTEQ organiza as palavras em um dendograma - que representa a quantidade e composição léxica de classes a partir de um agrupamento de termos - do qual se obtém a frequência absoluta de cada um deles e o valor de Qui-Quadrado agregado. Com a avaliação do dendograma, visualizou-se o conjunto de palavras agrupadas nas classes discursivas, sendo que as mais representativas foram aquelas com maior valor de Qui-Quadrado (relação de pertinência entre termo e classe). Em cada uma das classes atribuiu-se uma nomenclatura conceituando o conteúdo lexical obtido por meio da CHD, o qual buscou representar o aspecto semântico passível de interpretação a partir das classes.

\section{RESULTADOS E DISCUSSÃO}

$\mathrm{Na}$ Tabela 1 estão relacionadas às características dos candidatos à adoção e das crianças que desejam adotar. Quanto ao sexo da criança, sete $(53,8 \%)$ participantes apontaram não ter preferência; seis $(46,2 \%)$ declararam preferir adotar meninas. Com relação à cor de pele da criança, em dez entrevistas houve indicação e em três não houve preferências. Dos candidatos que indicaram preferência pela cor de pele, a predominante foi branca ou parda (8), compatível 
com a cor de pele declarada pelos pretendentes em 100\%. Dois entrevistados escolheram a cor de pele negra, sendo que um deles também optou pela parda, sendo também compatível com a cor de pele declarada ser a deles. Assim, constatase que a maioria dos candidatos prefere crianças de cor de pele semelhante à da sua própria cor.

Tabela 1. Perfil dos Participantes e Preferências Quanto às Características da Criança a ser Adotada

\begin{tabular}{llccc}
\hline & \multicolumn{2}{c}{ Candidato* } & Sexo & Características da Criança \\
& & Indiferente & Branca ou parda & Até 2 anos \\
\hline $\mathbf{1}$ & Feminino/casada/branca & Indiferente & Branca ou parda & 1 a 2 anos e meio \\
$\mathbf{2}$ & Feminino/casada/branca & Feminino & Negra & Até 4 anos \\
$\mathbf{3}$ & Masculino/solteiro/negro & Indiferente & Indiferente & Até 3 anos \\
$\mathbf{4}$ & Feminino/casada/negra & Indiferente & Indiferente & 1 a 4 anos \\
$\mathbf{5}$ & Feminino/divorciada/branca & Indiferente & Branca ou parda & Até 4 anos \\
$\mathbf{6}$ & Feminino/casada/parda & Indiferente & Branca ou parda & Até 1 ano e meio \\
$\mathbf{7}$ & Feminino/casada/parda & Feminino & Branca ou parda & Até 2 anos \\
$\mathbf{8}$ & Feminino/solteira/parda & Feminino & Branca ou parda & Até 2 anos \\
$\mathbf{9}$ & Feminino/divorciada/branca & Indiferente & Branca & Até 1 ano e meio \\
$\mathbf{1 0}$ & Feminino/casada/branca & Feminino & Parda ou negra & 2 a 3 anos \\
$\mathbf{1 1}$ & Masculino/casado/parda & Feminino & Indiferente & Até 2 anos \\
$\mathbf{1 2}$ & Feminino/casada/parda & Feminino & Parda & 1 a 2 anos \\
$\mathbf{1 3}$ & Feminino/casada/parda & & \\
\hline
\end{tabular}

*Características do candidato: sexo/estado civil/cor de pele autodeclarada.

Fonte: Elaborado pelos autores

Quanto ao perfil dos 13 entrevistados, 85\% $(n=11)$ são do sexo feminino. Com relação ao estado civil, nove (70\%) são casados; dois (15\%) são divorciados e dois (15\%) solteiros. No tocante à idade da criança, as solicitações foram bastante variadas. Dentre todos os participantes, dois pretendentes (15\%) indicaram desejarem adotar crianças de até quatro anos e um candidato $(7 \%)$ optou por adotar uma criança com até seis meses.

Os resultados podem ser comparados com os achados de Weber (2003), no Juizado da Infância e Juventude de Curitiba, que encontrou que $67 \%$ dos adotantes impõem como condição principal uma criança branca $(95 \%$ dos adotantes eram brancos), 19\% dizem aceitar uma criança "até morena", ou seja, preferem uma criança branca, mas aceitam uma morena clara; apenas 7\% dizem não ter preferência quanto à cor de pele da criança. Amim e Menandro (2007) afirmam ser importante a escolha que os adotantes fazem quanto à cor de pele, 
visto que essa opção por uma criança que se pareça com eles tem por suposição facilitar a identificação entre eles, os pais-, e os filhos. Muitas vezes, o perfil desejado pelos pretensos pais é bastante restritivo. Diante disso, sabe-se que o perfil da criança normalmente não corresponde ao idealizado, o que faz com que algumas características sejam pouco desejadas, ainda que se mostrem como as mais comuns entre as crianças passíveis de adoção (por exemplo, serem negras, apresentarem deficiências, problemas de saúde ou formarem grupo de irmãos), o que limita a possibilidade de serem inseridas em famílias adotivas (Guareschi, Strenzel, \& Bennemann, 2007).

Já com relação ao sexo e a idade da criança pretendida, o CNJ (2013) constatou que os candidatos cadastrados no CNA das regiôes Norte e Nordeste preferem crianças do sexo feminino; ao mesmo tempo, são flexíveis com relação à idade, aceitando crianças de até 5anos. Além disto, outras pesquisas também detectaram a preferência por recém-nascidos (Amim \& Menandro, 2007; Huber \& Siqueira, 2010; Weber, 2003). Um dos motivos atribuídos à escolha por bebês está relacionado ao desejo de vivenciar a etapa de desenvolvimento inicial da criança, em que se manifestam desde as primeiras expressóes faciais, além das primeiras falas e passos, construindo e registrando uma história familiar já a partir dos primeiros dias de vida do filho (Camargo, 2005; Huber \& Siqueira, 2010). Neste estudo, os dados encontrados diferem das pesquisas supracitadas, pois apenas um pretendente optou somente por recém-nascido (de até seis meses). Os demais participantes, embora aceitem os recém-nascidos, ampliaram a idade, havendo casos de até quatro anos $(n=3 ; 27 \%)$.

Enfim a lista de crianças passíveis de adoção obtida neste estudo foi, no geral, variada, indicando que a escolha do perfil pode ser um fator de limitação de possibilidades de adoção, o que reforça estudos anteriormente citados. Logo, julga-se necessário apontar a necessidade de que os candidatos sejam mais bem informados/esclarecidos quanto aos mitos associados à adoção, buscandose minimizá-los ou até eliminá-los. Eis - então - uma proposta passível de incorporação e/ou aperfeiçoamento nos cursos preparatórios e Grupos de Apoio para candidatos à adoção ou para os pais adotivos, tal como já lembrou Gondim et al. (2008).

\subsection{Análise das Classes}

O dendograma (Figura 1) demonstra a divisão das classes construídas por meio da CHD. O programa repartiu o corpus em 139 segmentos de texto, três classes, e em média 34,3 palavras por segmento. A classe 1 teve uma maior frequência $(36,4 \%)$, seguida das classes $2(34,5 \%)$ e 3 (29,1\%). A caracterização 
das classes deu-se da seguinte maneira: Classe 1: O Desejo pela Adoção; Classe 2: Dificuldades, Receios e Mitos frente à Adoção; e Classe 3: Expectativas em torno da Adoção.

Figura 1. Dendograma e classes lexicais das motivações, dificuldades e expectativas em torno da adoção

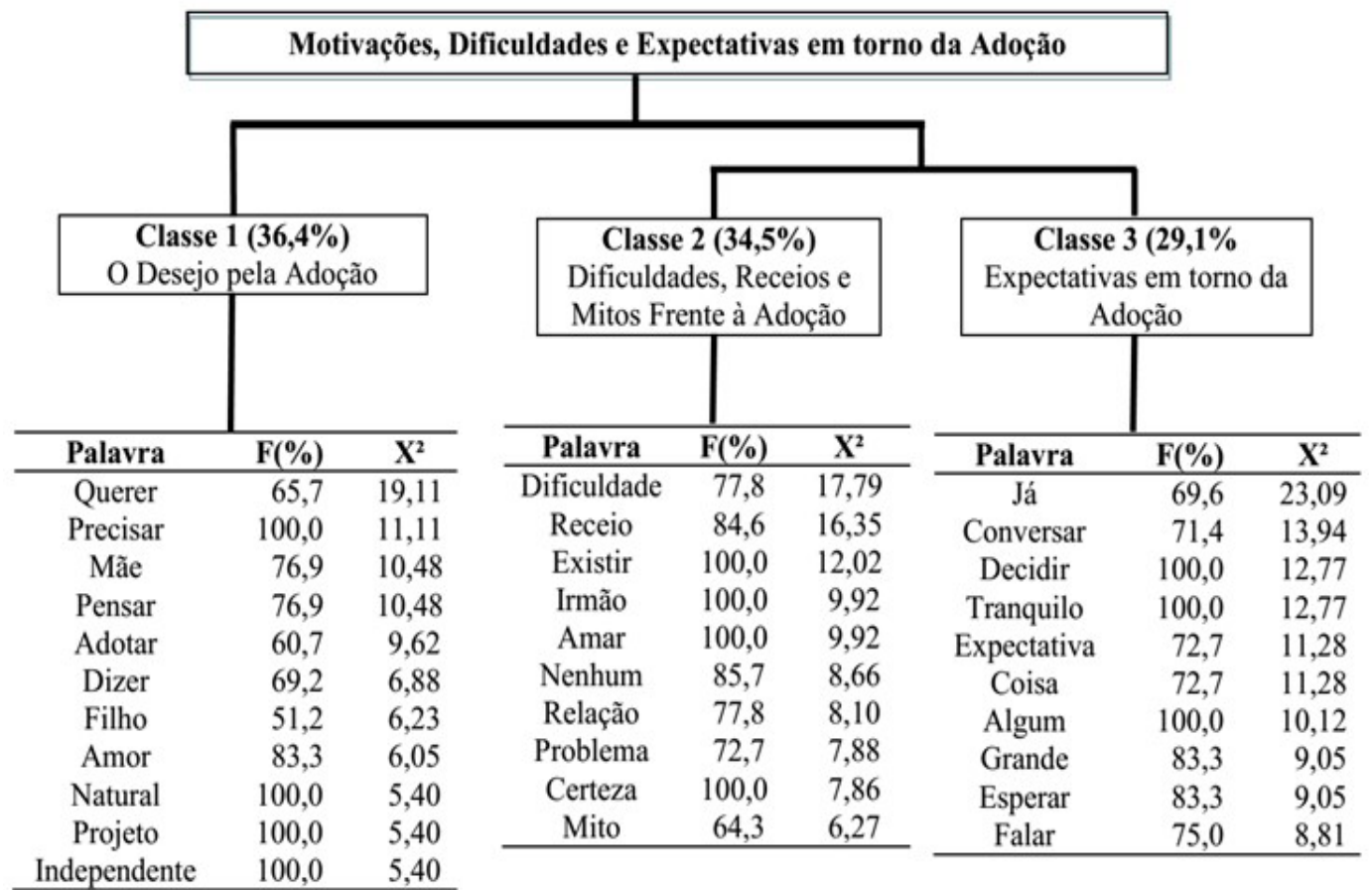

Fonte: Entrevistas com os participantes da presente pesquisa.

\subsection{Classe 1: O Desejo pela Adoção}

Essa foi a classe mais representativa no conjunto de segmentos de texto, trazendo como tema central as motivaçóes que levaram os pretendentes a decidirem pela adoção. Surgiram questôes como o desejo de ser mãe/pai, a infertilidade, o desejo de dar uma família a uma criança e de ter um filho pela adoção.

As dez palavras mais recorrentes e de maior Qui-Quadrado na classe foram: 'querer', 'precisar'; 'mãe'; 'pensar'; 'adotar', 'filho', 'amor', 'natural', 'projeto' e 'independente'. Sendo assim, sugere-se a seguinte sentença como discurso simbólico representativo da classe: Eu quero e preciso ser mãe/pai, por isso penso em adotar uma criança a qual receberá muito amor. É um projeto meu, independente, e não importa se não for natural (biológico). Quando a adoção é motivada pela infertilidade ou problemas de saúde, somada ao desejo de ser mãe/pai, as falas dos pretendentes à adoção mostram histórias de tentativas que resultaram na frustração de ter um filho pela via biológica, tal como se apreende da seguinte expressão: 
Primeiro o desejo de ser mãe. Mas, como fiz tratamentos que não deu certo, porque eu pensava que a gente tinha que tentar de tudo. Depois de quatro tentativas de fertilização, passei a correr risco, eu fiquei em paz com isso porque já tinha tentado. Então, a adoção foi uma coisa bem pensada, bem tranquila [Participante 9 (P9)].

Constata-se, pelos relatos, que a possibilidade de engravidar foi descartada somente após um tempo de tentativas e de insucesso quando da realização de tratamentos. Segundo Mariano e Rossetti-Ferreira (2008), a principal motivação apresentada para a adoção foi a infertilidade e outros problemas de saúde. Nessa perspectiva, a adoção tem uma dupla finalidade: a de permitir que a criança encontre uma nova família e um ambiente satisfatório para o seu desenvolvimento e a de possibilitar aos pais o exercício da paternidade e maternidade (Ishizawa \& Kubo, 2014; Park \& Hill, 2014; Schettini et al., 2006). Observou-se também que a maioria dos participantes relatou ter dificuldades para engravidar e que a adoção se tornou um projeto para que o desejo de ser mãe/pai se concretizasse, como observado no discurso a seguir:

Eu tentei engravidar ao natural, mas eu perdi com dois meses. Depois disso, eu tentei por um período, mas não consegui. Depois, tentei outro caminho, procurei a fertilização. Como não deu certo a fertilização, conversei com o meu esposo para a gente partir para a adoção. [...] Até porque como eu perdi o bebê e não posso mais engravidar, o que foi uma grande frustração para mim, mas eu acho que vai suprir esse meu lado materno. Eu quero muito ser mãe (p.10).

A adoção passa a ser cogitada diante de uma impossibilidade de gestar. Weber (2011) ressalta que - diante da perda de um filho - um diagnóstico de infertilidade ou esterilidade, o adotante, antes de pensar na adoção deve refletir sobre essas questões e ter um período de luto: aceitação do inevitável. Elaborados esses processos, assumir novas propostas de ação. É necessário enfrentar novos processos de aprendizagem das interações sociais e vinculações afetivas para o exercício da maternidade/paternidade por meio da adoção.

A infertilidade, um dos principais motivos para os que adotam, é causa de sofrimento (Lévy \& Carneiro, 2002; Park \& Hill, 2014). Desse modo, atentase para que futuros pais adotivos possam lidar com os sentimentos de perda, frustração e luto pelo filho biológico, antes que se proponham à adoção. Eles precisam 'se desligar' do filho (minimizar idealizações) que não pôde ser gerado, para amar e aceitar a futura criança/filho que virá.

A monoparentalidade foi mais um tema relatado no discurso dos participantes não casados. Uma expressão que remete a essa perspectiva pode ser observada no discurso a seguir: 
Primeiro foi essa questão da paternidade.[...] A ideia de adoção partiu, acho que eu tinha trinta e sete anos e foi amadurecendo, aí, eu me formei na faculdade, passei no concurso, comecei a ganhar um salário melhor e estabilizou na área financeira, o que me deu a segurança de assumir esse projeto. Queria que fosse conjunto, mas as circunstâncias da vida me levaram a ter esse projeto sozinho (P3).

Percebe-se na fala que a motivação para a adoção surgiu com o sentimento de paternidade, sendo que a iniciativa para se cadastrar só foi concretizado após a realização profissional e estabilidade financeira alcançada pelo participante. Lévy e Carneiro (2002) destacam o desejo de ser mãe monoparental e o medo da solidão como importantes motivadores para o projeto da adoção. Esses fatores encontram-se associados à ênfase na realização profissional, ao desejo de ampliar a família, além da necessidade de cuidar e de ser cuidada. Assim, tendo em vista a crescente demanda de adoção por indivíduos solteiros, nota-se que os adotantes buscam uma criança para inserir na condição de filho, diante do desejo de exercer a paternidade/maternidade, independentemente da conjugalidade.

No tocante ao sentimento altruísta, o discurso seguinte evidencia o desejo de dar uma família a uma criança: "É porque tem muita criança que precisa de amor. [...] e eu acho que se eu tentar amadurecer bastante esse lado assim, de querer adotar, porque não é só porque eu estou só, é porque tem muita criança que precisa de um lar, precisa de uma família" (P5). A literatura aponta que o altruísmo é um ato motivacional em que o indivíduo pouco pondera os seus desejos pessoais, mas valoriza as necessidades das crianças (Ebrahim, 2001; Ishizawa \& Kubo, 2014). Adotantes que tem motivação mais altruísta não se preocupam com características físicas da criança a ser adotada (Weber, 2011). Para Souza (2012), adotar não é ajudar uma criança abandonada, ou ser generoso, mas é aceitar ser pai ou mãe, com todas as dificuldades ou alegrias da maternidade/paternidade. Dito isto, acredita-se que a expectativa de um suposto "fazer o bem" pode entrar em contradição com as dificuldades que surgem no decorrer da vida enquanto pai/mãe-filho na relação entre o adotante e o adotado, pois, mais do que um ato altruísta, a adoção demanda aspectos afetivo-relacionais bem consubstanciados no desejo e expectativas acerca da adoção; que é o que se evoca nos relatos da classe seguinte.

\subsection{Classe 2: Dificuldades, Receios e Mitos frente à Adoção}

A referida classe diz respeito às dificuldades - ou ausência delas - que os pretendentes pensam que poderão ter no relacionamento com o futuro filho, e de possíveis mitos e receios que possuem em torno da adoção. As oito palavras que mais se destacaram nesta classe foram: 'dificuldade'; 'receio'; 'existir'; 'amar'; 
'nenhum', 'relação', 'problema' e 'mito'. Desse modo, seria possível construir duas frases representativas do discurso, em que uma aponta para uma ausência de dificuldades, suposta por alguns pretendentes; outra, para receios que eles têm em torno da adoção. Assim, indicam-se as seguintes frases, respectivamente: Acho que não terei nenhuma dificuldade na relação com meu futuro filho, pois vou amá-lo;e, por outro lado: Existem problemas (mitos) em torno da adoção; por isso, tenho receios.

A maior parte dos segmentos de texto analisados se refere a não existência de dificuldades, pois os pretendentes acreditam que virá a criança certa, que ela é muito desejada, e que o amor é suficiente no relacionamento entre pais e filhos, conforme o relato a seguir: "Não vejo dificuldades. Porque, assim, ele não está dentro de mim, mas ele é desejado desde antes de ter, de nascer" (P1). As falas refletem a idealização da relação entre pais e filhos, pontuando que tudo será impecável, e que não haverá conflitos; no entanto, as dificuldades existem em qualquer relação entre pais e filhos, independendo de serem adotivos. Tal noção pode ser extraída da seguinte fala de uma participante: "Dificuldades nas relações humanas sempre existem. Pai, filho, irmã e irmão. Toda relação tem as suas dificuldades. Vou trabalhar dentro de mim para evitar ao máximo esses atritos que poderão existir" (P3).

Para Silva e Silva (2012) não existe uma época específica para conflitos na relação pai/filho adotivo ocorrerem. Podem acontecer tanto no início da convivência, na fase de adaptação inicial, como quando o filho entra na adolescência. De acordo com Costa e Rossetti-Ferreira (2007), existem as dificuldades de adaptação, construção das regras, mudanças na rotina do casal e a relação de parentalidade e de afeto com uma criança maior. Daí, estratégias são necessárias a todas as faixas etárias para facilitar a vinculação afetiva, além de considerar a adaptação como um processo natural ao desenvolvimento familiar. No entanto, viu-se que - por meio de segmentos de falas - alguns participantes não mencionam a possibilidade de enfrentarem dificuldades no relacionamento com o futuro filho. De qualquer modo, sabe-se que a adoção de crianças requer, tanto da família adotante quanto da criança, capacidade de ajustamento, pois os pais podem se deparar com dificuldades afetivas de aproximação com a criança recém-chegada, que pode diferir da imaginada ou idealizada.

Muitos obstáculos são experimentados pelos candidatos à adoção. $\mathrm{Na}$ construção da identidade parental, faz-se necessário que os pretendentes abram mão do filho imaginado e idealizado e entrem num processo de identificação com o filho real, o que pode ser uma das primeiras dificuldades com as quais os requerentes se deparam em um processo de adoção (Silva $\&$ Silva, 2012). Dessa forma, as orientações dadas pelos profissionais dessa área são fundamentais para 
a compreensão dos adotantes no relacionamento com seus futuros filhos. Além disto, elas podem auxiliar os pretendentes a compreender o surgimento de futuros conflitos e, sobretudo, ajudar na busca por alternativas para contorná-los.

Alguns participantes declararam sentir receio e/ou medo em torno da adoção tardia. Uma expressão que remete a essa perspectiva pode ser observada no discurso adiante: "Quando é uma criança maior, a gente fica com receio dela não ser adaptar, rejeitar a família, mas eu acho que por ser bebê é mais difícil de acontecer isso" (p.8). Foram comuns relatos que, quando a criança é maior, há probabilidade tanto de a criança rejeitar a família substituta, como dos pais adotivos rejeitarem a criança; ainda assim, consideram a possibilidade de conquistar a confiança da criança e, aos poucos, ambos se adaptarem. No trecho de fala a seguir, observou-se o sentimento de receio, preocupação com relação ao que as pessoas irão pensar da criança; sobretudo, como os familiares tratarão o futuro filho, destacando que a sociedade ainda tem preconceito em torno da adoção tardia.

São muitos receios e assim, o preconceito é muito grande em relação à adoção. Eu tenho receio, às vezes, quando eu vejo minhas cunhadas, a família do meu esposo. [...] eu tenho receio de pensar, será que eles vão amar o sobrinho, meu filho, como ama os sobrinhos biológicos? [...] a gente tem medo da reação das pessoas, principalmente porque a gente optou por uma adoção tardia (P6).

$\mathrm{Na}$ pesquisa de Andrade, Costa e Rossetti-Ferreira (2006) - com pais adotantes - notou-se que existe o receio de influências genéticas desconhecidas no comportamento de seus filhos e preconceitos dos outros frente à adoção. Nesse caso, o preconceito partiu -muitas vezes - da própria família do pretendente, indo de encontro à expectativa de apoio e aceitação dos familiares e amigos para o sucesso da adoção (Dias, Silva, \& Fonseca, 2008). Com efeito, ressaltase a importância dos futuros pais, assim como os familiares, proporcionarem um espaço de acolhimento para receber o futuro filho, compreendendo que a criança pode ter vivenciado no passado, maus tratos, negligência, abusos, e que precisa ser amada e aceita (Otukaet al., 2013). Assim sendo, indica-se que todos da família - não só a nuclear, mas, também, a extensa - sejam preparados para uma possível adoção, pois, da mesma forma que podem ajudar e contribuir para a adaptação das crianças à família, podem servir de obstáculo.

No tocante às fantasias e mitos, as falas de dois entrevistados apontam para a vivência da criança no abrigo. Os discursos mostram que a criança pode carregar "vícios", tanto da criação da família biológica como dos costumes trazidos pela instituição de acolhimento, podendo gerar conflitos para a nova família. 
Constata-se - no discurso de um candidato - o receio de que a criança, em algum momento, possa entrar em conflito com a história de vida dela, colocando a questão da memória na determinação do comportamento.

[...] Então, acho que o nosso maior medo [...] é com, não quanto à historia da criança, mas o que ela conviveu dentro do abrigo. E a gente tem um pouco de preocupação com relação a esse contato com minha filha. [...] A gente conversava também [...] sobre a idade da criança que não pode ser maior que a nossa filha porque a gente pode ter problema. Acho que no fundo, a gente tem receio disso, mas que hoje já tá bem mais suave para mim [...] (p.4).

A temática da adoção tardia ainda permeia o imaginário da sociedade. Observou-se o medo que os pretendentes possuem das vivências das crianças, seus costumes e como isto vai se refletir na nova família, pois acreditam que a adaptação será mais complicada. Corroborando com os achados, Camargo (2005) aponta alguns fatores que dificultam a opção pela adoção tardia: que a família substituta sente medo de que a criança adotada não se adapte a uma nova família, por acreditar que já tenha formado seu caráter, personalidade, e por ter incorporado falta de limites, "vícios" e má educação e dificuldade de convivência. No entanto, as vivências de crianças e adolescentes que foram institucionalizados não podem servir de constatação para se dizer que trarão "vícios" e que não apresentará uma boa conduta por ter tido um passado doloroso (Otuka et al., 2013; Puretz \& Luiz, 2007).

Enfim, a partir do que foi visto nessa classe, julga-se pertinente destacar a necessidade da equipe que acompanha os pretendentes, assim como os Grupos de Apoio, enfatizar a desconstrução de mitos e preconceitos relacionados à adoção, uma vez que, dificuldades surgem independentemente se a família se constituiu pela consanguinidade, ou não.

\subsection{Classe 3: Expectativa em torno da Adoção}

Os conteúdos desta classe se referiram às expectativas que os futuros pais possuem em torno da adoção. Percebeu-se que eles possuem expectativas quanto à chegada do filho, ansiedade quanto à demora do processo e a importância do apoio de um profissional da área. As palavras mais recorrentes nos discursos foram: 'já'; 'conversar'; 'decidir'; 'tranquilo'; 'expectativa' e 'grande'. Dessa forma, propõe-se a seguinte sentença como discurso simbólico da classe: Já conversei sobre a adoção e estou tranquilo quanto à decisão que tomei; por isso, estou com grande expectativa para que o futuro filho chegue logo. 
O discurso dos participantes demonstrou que, antes de decidirem pelo projeto da adoção, conversaram com seus cônjuges e/ou familiares. Um trecho da fala de uma participante, por exemplo, evidencia diálogos com seu cônjuge e que a espera pela criança fez parte do seu cotidiano: "Passamos três meses conversando sobre o assunto e depois fomos lá na Vara se cadastrar. Tenho expectativas de ver meu filho chegando em minha casa"(P2). Muitas vezes os pais adotivos demonstram expectativas com relação ao futuro filho, além de planejarem a recepção da criança e a educação desta. A partir dos relatos, notou-se juntoàs expectativas positivas com relação à adoção, certa ansiedade da chegada do filho. Os pretensos adotantes vivenciam o tempo de espera pela criança com preocupações, expectativas e frustrações (Schettini et al., 2006). Há, então, muita esperança, visto que os pretensos pais não tem conhecimento de quando o filho chegará (Souza, 2012).

Durante o tempo de espera, é de suma importância a participação em Grupos de Apoio, pois os futuros pais vivenciarão sentimentos e emoçôes despertados pela adoção, além de trocar experiências entre si e compartilhar conhecimentos (Scorsolini-Comim, Amato, \& Santos, 2006). Dito isso, no trecho de fala a seguir, observa-se que os próprios participantes reconhecem a importância de se inserir nesses grupos para amenizar as preocupações, ansiedade e expectativas da chegada do futuro filho: "[...]eu acho que o psicólogo (Grupo) é muito importante para conversar tanto com a criança como conosco" (p.6).

Enfim, estudos preconizam a necessidade de uma rede de suporte e apoio a preparação de famílias adotantes através de Grupos/Programas de Apoio à adoção (Brooks, Allen, \& Barth, 2002; Dhami, Mendel, \& Sothmann, 2007; Denby et al., 2011; Grotevant \& McDermott, 2014; Sánchez-Sandoval et al., 2012; Santos, 2004). A troca de experiência pelos futuros pais e as orientações profissionais (psicólogos e assistentes sociais) são ferramentas de mudanças, podendo esclarecer dúvidas no contexto da adoção, como também diminuir a ansiedade na espera pelo filho, tornando a adoção um processo, quiçá, menos inquietante.

\subsection{Análise Geral das Classes: Percepção dos Futuros Pais quanto à Adoção}

O objetivo deste estudo foi investigar os motivos, as dificuldades e expectativas que influenciam na prática da adoção, bem como o perfil da criança pretendida pelos candidatos. Em síntese, observam-se resultados similares àqueles anteriormente descritos pela literatura neste âmbito, com base em estudos anteriores e realizados em outros contextos. 
Com relação às características das crianças pretendidas pelos participantes, apesar da ausência de indagações diretas sobre as motivaçôes que levaram os pretendentes a escolher as características do futuro filho, observou-se concordância com a literatura, que aponta para preferências por meninas, brancas ou pardas e menores que cinco anos. Estes dados estiveram presentes tanto nas entrevistas quanto no próprio cadastro do juizado. Visto que os pretendentes à adoção estão inseridos na sociedade, o processo de escolha das características do filho adotivo é marcado também por expectativas compartilhadas socialmente, tais como estereótipos, preconceitos e mitos, atuando como limitação das possibilidades da adoção. Os resultados indicam - ainda - que a iniciativa ao projeto da adoção advém de várias motivaçôes: como uma alternativa para tentar ultrapassar os sentimentos de perda e de frustração impostos pela infertilidade; como o desejo de exercer a maternidade/paternidade; também, o sentimento altruísta de querer dar uma família a criança. Além disto, de acordo com os trechos de fala, a idealização da relação entre pais e filhos, os receios quanto à adoção tardia indicaram que os mitos ainda permeiam no imaginário dos futuros pais.

Quanto às limitações desta pesquisa, acredita-se que o número reduzido de entrevistados assume maior destaque. A respeito dessa limitação, constatou-se a existência de grande dificuldade no acesso aos candidatos e, principalmente por isso, a consequente redução da quantidade de participantes. Muitos deles alegaram indisponibilidade à participação na pesquisa ou mesmo já haviam indicado isso no cadastro para adoção. Entende-se e respeita-se o fato de que a escolha em colaborar com os estudos científicos é de livre arbítrio; no entanto, parece que precisam ser mais bem investigados os motivos que levam às pessoas a não desejar se envolver com tais estudos, uma vez que - sem esse contato - tornase extremamente complexo aprofundar conhecimentos acerca das temáticas ligadas à adoção. Diante disso, sugere-se que futuras investigações possam não só se direcionar ao tema da adoção em si; também, conhecer os motivos que levam os pretensos pais a não consentirem sua participação nas pesquisas; desde as crenças que possuem a respeito das atividades científicas passíveis de consecução nesse momento do processo de adoção, até entraves, receios e preconceitos que fazem com que rejeitem colaborar com os estudos.

De acordo com o que foi dito, julga-se importante ressaltar que estudos sobre as motivações, dificuldades e perspectivas para o futuro e justificam na necessidade de conhecer como se estruturam as percepções destes pretendentes acerca da adoção, buscando não só primar pela proteção da criança, mas, também, facilitar a experiência dos próprios pais. Apenas a partir desse conhecimento será possível pensar mais adequadas estratégias de preparação dos futuros pais e da própria 
sociedade para lidar com este processo, a fim de promover o direito reconhecido à criança de viver em uma família e não institucionalizada.

Cabe enfatizar a necessidade de preparar os pretendentes à adoção, pois, segundo Gondim et al. (2008), esse preparo possibilita que eles repensem as suas exigências quanto às características (físicas e psicológicas) da criança desejada, de forma a permitir a facilitação do processo, ampliando-se as possibilidades, a responsabilidade e a responsividade na condução dos processos de adoção, de modo que o bem-estar e o desenvolvimento da criança sejam sempre preservados. Em suma, vê-se que fantasias distorcidas em torno da adoção levam os indivíduos a terem critérios muito restritivos quanto ao filho que pretendem adotar, o que dificulta, certamente, a conciliação de interesses entre quem está passível de ser adotado e os pretensos adotantes. Enfim, quão mais limitativo o funil, mais difícil a concretização da adoção. 


\section{REFERÊNCIAS}

Amim, I. D. \& Menandro, P. R. M. (2007). Preferências por características do futuro filho adotivo manifestadas por pretendes à adoção. Interação em Psicologia, 11(2), 241-252.

Andrade, R. P., Costa, N. R. A. \& Rossetti-Ferreira, M. C. (2006). Significações de paternidade adotiva: um estudo de caso. Paidéia, 16(34), 241-252.

Brooks, D., Allen, J. \& Barth, R. P. (2002). Adoption services use, helpfulness, and need: a comparison of public and private agency and independent adoptive families. Children and Youth Services Review, 24(4), 213-238.

Camargo, B. V. \& Justo, A. M. (2013). Iramuteq: um software gratuito para análise de dados textuais. Temas em Psicologia, 21(2), 513-518.

Camargo, M. L. (2005). A adoção tardia no Brasil: Desafios e perspectivas para o cuidado com crianças e adolescentes. Em Proceedings of the 1th Simpósio Internacional do Adolescente, São Paulo (SP) [online].

Conselho Nacional de Justiça (2013). Encontros e desencontros da adoção no Brasil: uma análise do Cadastro Nacional de Adoção do Conselho Nacional de Justiça. Brasília: CNJ.

Costa, L. F. \& Campos, N. M. V. (2003). A avaliação psicossocial no contexto da adoção: Vivências das famílias adotantes. Psicologia: Teoria e Pesquisa, 19(3), 221-230.

Costa, N. R. A. \& Rossetti-Ferreira, M. C. (2007). Tornar-se pai e mãe em um processo de adoção tardia. Psicologia: Reflexão e Crítica, 20(3), 425-434.

Denby, R. W., Alford, K. A. \& Ayala, J., (2011). The journey to adopt a child who has special needs: Parent's perspectives. Children and Youth Services Review, 33(9), 1543-1554.

Dhami, M. K., Mandel, D. R. \& Sothmann, K. (2007). An evaluation of postadoption services.Children and Youth Services Review, 29(2), 162-179.

Dias, C. A. S. B., Silva. R. B. V. \& Fonseca, C. M. S. M. S. (2008). A adoção de crianças maiores na perspectiva dos pais adotivos. Contextos Clínicos, 1(1),2835 . 
Ebrahim, S. G. (2001). Adoção tardia: Altruísmo, maturidade e estabilidade emocional. Psicologia: Reflexão e Crítica, 14(1), 73-80.

Gondim, A. K., Crispim, C. S., Fernandes, F. H. T., Rosendo, J. C., Brito, T. M. C. de, Oliveira, U. B., Nakano, T. C. (2008). Motivação dos pais para a prática da adoção. Boletim de Psicologia, 58(129), 161-170.

Grotevant, H.D. \& McDermott, J.M. (2014, September). Adoption: biological and social process linked to adaptation. Annual Review of Psychology, 65, $235-265$.

Guareschi, N. M.F., Strenzel, J. C. \& Bebbemann, T. (2007). Quem está apto? A prática da adoção e marcadores identitários. Aletheia, 25, 163-176.

Huber, M. Z. \& Siqueira, A. C. (2010). Pais por adoção: a adoção na perspectiva dos casais em fila de espera. Psicologia: Teoria e Prática, 12(2), 200-216.

Ishizawa, H. \& Kubo, K. (2014). Factors affecting adoption decisions: child and parental characteristics. Journal of Family Issues, 35(5), 627-653.

Jerome, K. \& Sweeney, K.A. (2014). Birth parents'portrayals in children's adoption literature. Journalof Family Issues, 35(5), 677-704.

Lei no 12.010 de 3 de agosto de 2009. (2009, 4 agosto). Dispóe sobre adoção; altera as Leis $\mathrm{n}^{\mathrm{os}}$ 8.069, de 13 de julho de 1990 - Estatuto da Criança e do Adolescente, 8.560, de 29 de dezembro de 1992; revoga dispositivos da Lei n⿳0 10.406, de 10 de janeiro de 2002 - Código Civil, e da Consolidação das Leis do Trabalho - CLT, aprovada pelo Decreto-Lei oㅜ 5.452, de $1^{\circ}$ de maio de 1943; e dá outras providências. Diário Oficial da União, Brasília.

Levy, L. \& Carneiro, T. F. (2002). Famílias monoparentais femininas: um estudo sobre a motivação de mulheres que adotam. Interação em Psicologia, 6(2), 243-250.

Mariano, F. N. \& Rossetti-Ferreira, M. C. (2008). Que perfil da família biológica e adotante, e da criança adotada revelam os processos judiciais? Psicologia: Reflexão e Crítica, 21(1), 11-19.

Merçon-Vargas, E. A., Rosa, E.M., \& Dell'Aglio, D. D. (2011). Adoção nacional e internacional: processos proximais no período de convivência. Salud \& Sociedad, 2(3), 268-283. 
Otuka, L. K., Scorsolini-Comin, F. \& Santos, M.A. (2013). Adoção tardia por casal divorciado e com filos biológicos: novos contextos para a parentalidade. Estudos de Psicologia, Campinas, 30(1), 89-99.

Park, N.K., Hill, P.W. (2014). Is adoption an option? The role of importance of motherhood and fertility help-seeking in considering adoption. Journal of Family Issues, 35(5), 601-626.

Puretz, A. \& Luiz, D. E. C. (2007). Adoção tardia: desafios e perspectivas na sociedade contemporânea. Emancipação, 7(2), 277-301.

Reppold, C. T. \& Hutz, C. S. (2003). Reflexão social, controle percebido e motivações à adoção: características psicossociais das mães adotivas. Estudos de Psicologia, 8(1), 25-36.

Salvaterra, F. \& Veríssimo, M. (2008). A adopção: o direito e os afectos: caracterização das famílias adoptivas do Distrito de Lisboa. Análise Psicológica, 26(3), 501-517.

Sánches-Sandoval, Y. \& Palacios, J. (2012). Stress in adoptive parents of adolescents. Children and Youth Services Review, 34(7), 1283-1289.

Santos, D. C. S. (2010). Adoção tardia: uma realidade em Sergipe. Revista Esmese, 14, 183-208.

Santos, M. A. (2004). Percepções acerca de uma experiência em grupo de apoio a adotantes: uma construção sistêmica. Revista da SPACGESP, 5(5), 29-36.

Schettini, S. S. M., Amazonas, M. C. L. A. \& Dias, C. M. S. B. (2006). Famílias adotivas: identidade e diferença. Psicologia em Estudo, Maringá, 11(2), 285293.

Scorsolini-Comin, F., Amato, L. M. \& Santos, M. A. (2006). Grupo de apoio por casais pretendentes à adoção: a espera compartilhada do futuro. Revista da SPAGESP, 7(2), 40-50.

Silva, J. A. (2009). Adoção de crianças maiores: percepçôes e vivências dos adotados. (Dissertação de mestrado). Pontifícia Universidade Católica de Minas Gerais, Programa de Pós-Graduação em Psicologia, Belo Horizonte. Recuperado a partir de http://www1.pucminas.br/documentos/dissertacao_ jaqueline_araujo.pdf 
Silva, J. C. B. \& Silva, E. C. B. (2012). Adoção: da idealização ao fracasso. Em proceedings of the Congresso Internacional Interdisciplinar em Sociais e Humanidades. (p. 1- 17) Niterói (RJ): ANINTER-SH/ PPGSD-UFF.

Silva, L. A., Mesquita, D. P. \& Carvalho, B. G. E. (2010). Investigando o processo de adoção no Brasil e o perfil dos adotantes. Revista de Ciências Humanas, 44(1), 191-204.

Souza, H. P. (2012). Adoção tardia: devolução ou desistência de um filho? A necessária preparação para adoção. Curitiba: Juruá.

Vanalli, A. C. G. \& Santana, A. M. (2009). O processo de adoção: Conhecendo as vivências das famílias adotantes. Revista Uniara, 11(21/22), 158-163.

Weber, L. N. D. (2003). Aspectos psicológicos da adoção. Curitiba: Juruá.

Weber, L. N. D. (2011). Adote com carinho: um manual sobre aspectos sociais da adoção. Curitiba: Juruá. 